\title{
CONTRIBUIÇÕES DA EDUCAÇÃO HISTÓRICA PARA A APRENDIZAGEM EM HISTÓRIA ${ }^{1}$
}

\author{
CONTRIBUTIONS OF HISTORICAL EDUCATION FOR HISTORY LEARNING
}

Ana Paula Rodrigues Carvalho²

\begin{abstract}
RESUMO: O presente artigo propõe debater acerca das teorias da aprendizagem behaviorista, cognitivista e construtivista à luz da Educação Histórica. Enquanto as teorias psicológicas buscam explicar a aprendizagem histórica a partir da cognição ou de preceitos associacionistas, a Educação Histórica, enquanto campo de pesquisa, remete a aprendizagem à própria epistemologia da História. A partir desta perspectiva, o ensino de História deixa de ser validado pela quantidade de informações que o aluno é capaz de reter e passa a objetivar a progressão do pensamento histórico e o desenvolvimento da literacia histórica dos alunos. Neste sentido, a relação que os alunos estabelecem com os conceitos e categorias vinculados à racionalidade histórica assumem relevância para formação de sujeitos capazes de vincular a experiência do tempo à sua própria subjetividade, dotando-a de significância e usos para sua vida prática.
\end{abstract}

Palavras - chave: Educação Histórica. Literacia. Construtivismo social. Behaviorismo. Cognitivismo.

\begin{abstract}
This article proposes to discuss about the behavioral, cognitivist and constructivist learning theories through the light of History Education. While the psychological theories seek to explain the historical learning from either the cognition or associationist precepts, the History Education, as a researching field, refers the learning to history epistemology itself. From this perspective, history teaching stops its validation by the amount of information that the student can retain and starts to aim the student's historical thinking progression and their historical literacy development. In this sense, the relation that the students stablish with the concepts and the categories linked to the historical rationality assumes relevance for the attainment of the formation of subjects capable of linking the time experience to their own subjectivity endowing it with significance and uses for their practical life.
\end{abstract}

Key-words: History Education. Literacy. Social constructivism. Behaviorism. Cognitivism.

\footnotetext{
${ }^{1}$ Este artigo foi retirado da dissertação de mestrado da autora intitulada: "Porque o Fascismo é como o Nazismo na Itália e o Mussolini é um Hitler italiano": análise das ideias históricas de alunos do ensino médio da cidade de Guarapuava - PR, desenvolvida no Programa de Pós-Graduação em História da UEL (Universidade Estadual de Londrina), sob orientação da Professora Dra. Márcia Elisa Teté Ramos e com financiamento da CAPES.

2 Doutoranda em História pela Universidade Federal de Mato Grosso (UFMT). Bolsista FAPEMAT. Membro do Laboratório de Ensino de História (LEHIS/UNICENTRO).
} 


\section{Introdução}

Várias são as interrogações acerca de como se aprende ou de como se origina o conhecimento. As respostas dadas a estas inquietações são diversas e resultaram em teorias da aprendizagem. Neste artigo, propõe-se discutir a respeito de três vertentes, a saber: a teoria behaviorista, a teoria cognitivista, e o construtivismo. Não se pretende, aqui, discorrer de forma exaustiva e aprofundada sobre estas três teorias da aprendizagem, mas, sim, trazer em pauta algumas das suas principais características e implicações pedagógicas para sala de aula. Em seguida, a discussão se concentrará sobre a Educação Histórica e a forma que este campo tem contribuído para transformar o Ensino de História.

A Educação Histórica é uma "[...] área de investigação centrada nas questões relacionadas à cognição e metacognição histórica, tendo como fundamento principal a própria epistemologia da História" (CAINELLI; OLIVEIRA, 2011, p. 127). Não se trata de uma nova teoria da aprendizagem, mas de um campo de pesquisa que, por meio do construtivismo social, pensa o Ensino de História a partir de pressupostos ancorados na racionalidade da ciência da História.

Segundo Flávia Caimi, o que diferencia os Estudos Cognitivos da Educação Histórica, é o fato de que para explicar a aprendizagem histórica, a primeira parte da cognição e a segunda parte da epistemologia da História. São pontos de partida diferentes, mas que têm como prioridade "[...] a noção de que o aprender implica em um processo construtivo/reconstrutivo do sujeito, dado que o conhecimento não se copia, não se transmite, mas se estrutura progressivamente nas interações qualificadas entre o sujeito, 0 meio físico, social, simbólico" (CAIMI, 2009, p. 65). 


\section{Teoria Behaviorista}

Segundo Ignacio Pozo (2006) as concepções de aprendizagem empiristas têm origem na tradição grega, iniciada por Aristóteles. Este teria substituído a teoria das ideias inatas, ou seja, de que o conhecimento é sempre uma projeção das nossas ideias inatas ou puras - como exposto por Platão no mito da caverna -, pela da tabula rasa. O princípio da tabula rasa se baseia na asserção de que todo "[...] conhecimento tem sua fonte fora do indivíduo e [...] é interiorizado através dos sentidos" (KAMII, 1990, p. 24).

Para Pozo (2006), Aristóteles pode ser considerado o pai do associacionismo e, nos séculos XVII e XVIII, com Hume, Locke e Hobbes alcançou sua máxima expressão na Filosofia. Acreditava-se que o conhecimento era alcançado por meio de associações realizadas com base nos princípios de semelhança, causalidade e contiguidade espacial e temporal.

$\mathrm{Na}$ Psicologia da Aprendizagem, os preceitos advindos do associacionismo foram denominados de Behaviorismo. Este movimento foi caracterizado "[...] por la aplicación de su paradigma objetivista, basado en los estudios de aprendizaje mediante condicionamiento, que considera innecesario el estudio de los processos mentales superiores para la comprensión de la conducta humana" (POZO, 2006, p. 18). A Psicologia Behaviorista é definida como a "ciência do comportamento" (observável) e a conduta é percebida como resultado de pressões externas ou estímulos. Segundo o behaviorismo, as reações obtidas a partir de determinados estímulos poderiam ser previstas e controladas.

Esse movimento foi caracterizado por uma grande dispersão teórica que deu origem a diversas facções dentro do Behaviorismo. Estas podem ser divididas, grosso modo, entre Behaviorismo extremo ou radical que negava a existência da consciência e o Behaviorismo metodológico que não negava a existência da consciência, mas acreditava que os processos mentais não poderiam ser considerados objeto de pesquisa por não serem observáveis empiricamente. Para Watson, criador da vertente do Behaviorismo metodológico, o Behaviorismo era uma "[...] psicologia experimental, 
objetiva, científica e determinista, cuja única fonte seria o comportamento diretamente observável" (LIMA, 1990, p. 6).

Conforme Pozo (2006), não obstante as diversas correntes teóricas que surgiram dentro do Behaviorismo é possível delinear algumas características que lhes eram comuns. O associacionismo, por exemplo, pode ser considerado uma característica central dentro do Behaviorismo. Se, inicialmente, todos são tábulas rasa que adquirem conhecimento por meio de mecanismos de associações, torna-se fundamental, dentro do behaviorismo, entender de que forma a aprendizagem é possível. Portanto, vários estudos foram realizados com o intento de estabelecer os parâmetros dessas associações.

Outra característica do Behaviorismo é o condicionamento alcançado por meio de uma combinação entre estímulo e resposta. Esta característica está intrinsecamente ligada ao associacionismo já que "[...] toda conducta, por compleja que sea, es reducible a una serie de asociaciones entre elementos simples, en este caso, estímulos y respuestas" (POZO, 2006, p. 28). No Behaviorismo "[...] o Homem é pensado como um ser que responde a estímulos exteriores de um modo mais ou menos automático e fortuito" (GAGO, 2012, p. 13). Portanto, a aprendizagem é vista como uma forma de mudar condutas por meio de estímulos capazes de provocarem reações específicas.

A Lei do Efeito, cunhada por Edward Thorndike, explicita de que forma a conexão entre estímulo e reação pode ser reforçada ou inibida quando o empenho é recompensado ou punido. Ou seja, é mais provável que a mesma reação seja obtida se esta for recompensada pelo professor (reforço positivo). Ao contrário, uma dada reação será coibida quando resultar em situações punitivas para o aluno (reforço negativo).

Outro atributo do Behaviorismo é a ênfase no meio em que o aluno está inserido, por destacar o fato que a aprendizagem se inicia e é controlada pelo ambiente. Para Pozo (2006), este pressuposto é coerente quando se considera a passividade do aluno que se limita a responder a estímulos externos, afinal, segundo o Behaviorismo, a aprendizagem não é algo intrínseco ao Homem, pois necessita do impulso do ambiente. Burrhus 
Frederic Skinner afirmava que para se obter uma aprendizagem satisfatória era necessário identificar as condições estimuladoras capazes de obter condutas desejáveis.

Outra característica atribuída ao Behaviorismo é a Equipotencialidade. Segundo este princípio, "[...] las leyes del aprendizaje son igualmente aplicables a todos los ambientes, especies e individuos. Lo que equivale a afirmar que sólo existe una única forma de aprender: la asociación" (POZO, 2006, p. 29). Como consequência todos os organismos da mesma espécie se equivalem entre si, e a especificidade de cada um é anulada. Outro ponto importante é a asserção que a aprendizagem está submetida somente à leis de associação, sendo assim qualquer estímulo ou resposta são equivalentes e qualquer estímulo pode ser associado a outro estímulo ou resposta independentemente do conteúdo. A única lei que importa é a da associação vinculada aos estímulos dados.

Segundo Pozo, em meados do século XX, houve um retrocesso das posições behavioristas em favor da Psicologia Cognitivista. No entanto, como afirma o autor, "[...] el muerto goza de una salud aceptable, al menos para estar muerto" (POZO, 2006, p. 19). Esta declaração alude ao fato que muitas das práticas pedagógicas perpetradas ainda hoje em sala de aula provém de pressupostos behavioristas.

Fernando Becker (1993) em uma pesquisa realizada com professores, nos quais estes eram questionados sobre o que é o conhecimento, identificou a persistência de concepções behavioristas em sala de aula. Conforme o autor, princípios empiristas foram encontrados nas falas de professores desde a pré-escola até universidades, incluindo professores de programas de pósgraduação stricto sensu. Na fala dos professores foi recorrente a ideia, por exemplo, de que o conhecimento "se dá sempre via cinco sentidos, de uma ou outra maneira" ou "se dá à medida que as coisas vão aparecendo e sendo introduzidas por nós nas crianças". O conhecimento é, também, considerado como uma reação resultante de estímulos dados pelo educador; outro professor afirmou que "o aluno é como a anilina no papel em branco que a gente tinge: passa para o papel - o aluno elabora, coloca com as próprias palavras" (BECKER, 1993, p. 89). 
A partir destes exemplos é nítido como o aluno ainda é considerado uma tabula rasa, visto que o conhecimento se encontra fora dele e se concentra na figura do professor ou nos livros. Segundo Marta Darsie (1999, p. 11), um dos indícios da presença do behaviorismo no ensino é a manutenção da "disciplina do silêncio, só o professor fala, o aluno tem que ouvir; o professor mostra, o aluno tem que olhar. Ver e ouvir em silêncio, sem desviar os sentidos para que o conhecimento possa 'entrar' no indivíduo".

Trata-se de um método de aprendizagem mecanicista pautado, principalmente, em exercícios de repetição que estimula a memorização dos conteúdos. Nesta perspectiva, o aluno não é considerado um sujeito ativo no processo de aprendizagem, pois é tido como um recipiente vazio e suscetível a modificações decorrentes de estímulos nos quais suas reações seriam recompensadas ou punidas de acordo com os objetivos postos pelo professor.

\section{Teoria cognitivista}

A Psicologia Cognitiva, contrariamente ao Behaviorismo, enfatiza os processos internos. Volta-se para o processo de cognição com o qual o sujeito atribuiu sentidos à realidade. Analisa o processo de compreensão, modificação e usos da informação adquirida e investiga as leis gerais que enseja este mecanismo. Segundo Pozo,

[...] en lugar de posiciones ambientalistas, el procesamiento de información defenderá la interacción de las variables del sujeto y las variables de la tarea o situación ambiental a la que está enfrentado el sujeto. Por último, el sujeto del conductismo, fundamentalmente passivo y receptivo, se convierte en un procesador activo de información, en un «informívoro» que busca y reelabora activamente información (POZO, 2006, p. 44).

De acordo com a Teoria Cognitivista, a aprendizagem não se limita a uma simples resposta a estímulos externos. Trata-se de um processo ativo de interpretação e organização do conhecimento adquirido, o que comporta uma modificação cognitiva no sujeito. Conforme Marilia Gago, o educando é "[...] um agente ativo, capaz de criar o seu próprio mundo e de evoluir, 
continuamente, à medida da experiência que vai adquirindo e vivenciando" (GAGO, 2012, p. 15).

A corrente cognitivista apresenta um núcleo teórico razoavelmente coerente, no entanto é possível dividir esta corrente em dois grupos. Alguns dão ênfase aos processos cognitivos como Jerome Bruner, Jean Piaget e David Ausubel, enquanto outros se concentram em aspectos que envolvem a esfera afetiva, também denominados de humanistas, como Carl Rogers e George Kelly. A seguir, discorrer-se-á, de forma mais específica, sobre as principais contribuições para a Educação de Bruner, Piaget e Ausubel.

Para Jerome Bruner, a aprendizagem deveria ser reputada como um processo de descoberta (Discovery learning). De acordo com este pensamento, o conteúdo escolar deveria ser posto como um problema a ser resolvido, com lacunas a serem preenchidas. Segundo Bruner, por meio da experimentação, da observação, da pesquisa, e de debates, o conhecimento adquirido poderia ser, enfim, organizado e colocado em relação aos saberes já possuídos pelo sujeito. Para o autor,

\begin{abstract}
A participação ativa no processo de aprendizado da criança pode resultar nos seguintes benefícios: aumento do potencial intelectual, bem como viabilizar mais rapidamente a informação adquirida para solucionar problemas, e favorecer a construção do conhecimento através das atividades de aprendizagem visto que o este seria uma recompensa intrínseca da própria descoberta ${ }^{3}$ (BRUNER, 1961, p. 24).
\end{abstract}

Para que a aprendizagem ocorra, Bruner ressalta a importância dos problemas e questões utilizados para encaminhar o processo de descoberta. É necessário que estes sejam considerados relevantes a nível pessoal e social, desta forma os alunos se sentiriam mais envolvidos no seu próprio processo de aprendizagem.

Assim como Bruner, Jean Piaget também acreditava que a aprendizagem é um processo de exploração e descoberta. Entretanto, Piaget não desenvolveu exatamente uma teoria educativa, mas uma teoria sobre o

\footnotetext{
${ }^{3}$ Tradução livre da autora. No original "The active participation in the learning process by the child might result in the following hypothesized benefits: an increase in intellectual potency so as to make the acquired information more readily viable in problem solving, the enaction of the learning activities in terms of the intrinsic reward of discovery itself" (BRUNER, 1961, p. 24).
} 
desenvolvimento cognitivo e de como os esquemas mentais evoluem ao longo dos anos.

Conforme Piaget, o desenvolvimento cognitivo do sujeito ocorre por meio de dois processos: o de assimilação e o de acomodação. Não importa em que estágio cognitivo se encontra o indivíduo, o mecanismo de aquisição de conhecimento é sempre pautado, em um primeiro momento, pela assimilação, ou incorporação de algo novo e, em seguida, pela acomodação, no qual o sujeito modifica seus esquemas em decorrência da incorporação da nova informação. De acordo com Circe Bittencourt,

O funcionamento constante dos dois processos assimilação/acomodação - corresponde ao princípio de desenvolvimento das estruturas mentais e ao crescimento da capacidade cognitiva: o sujeito responde por meio de compensações ativas aos desafios exteriores, aos desequilíbrios criados pelos problemas enfrentados, pelos conflitos, e esse "reequilíbrio" promove o desenvolvimento intelectual (BITTENCOURT, 2011, p. 185).

Sendo assim, o desenvolvimento intelectual ocorre por meio da assimilação, da acomodação e pelo processo de equilibração "[...] que se produz quando se tenha alcançado um equilíbrio entre as discrepâncias ou contradições que surgem entre a informação nova que assimilamos e a informação que já tínhamos e a qual nos acomodamos" (CARRETERO, 1997, p. 25). Como visto, portanto, a aprendizagem não é resultado de memorização ou cópia, mas resulta de uma organização mental.

Um aspecto muito importante da teoria de Piaget diz respeito aos estágios de desenvolvimento cognitivo: Sensório-motor, Pré-operacional, Operacional concreto e Operacional-formal. Estes estágios de desenvolvimento têm caráter sequencial e integrativo, no sentido de que sua sequência é invariável e integrativa porque cada fase sucessiva é uma extensão da anterior. Ou seja, "[...] no processo do conhecimento, nada aparece sem uma ligação com as conquistas que precederam a que está sendo alcançada aqui e agora, e que toda aquisição nova prepara o caminho para os progressos subsequentes" (SEBER, 1991, p. 16). A aprendizagem não é uma cópia ou fruto de memorizações e sim resultado de uma modificação interna nos esquemas que o sujeito possui. Conforme Mario Carretero (1997, p. 22), "[...] o desenvolvimento cognitivo pode ser 
compreendido como aquisição sucessiva de estruturas lógicas, cada vez mais complexas, que subjazem às distintas áreas e situações que o sujeito é capaz de ir resolvendo à medida que cresce".

Uma das críticas feitas a Piaget diz respeito ao fato de que a evolução cognitiva estaria vinculada à maturidade física. Este aspecto da sua teoria foi criticado por estudos como o de Vygotski e de outros construtivistas que afirmavam ser o social e as experiências pessoais a base para a aprendizagem. Desta forma, a idade não é o fator determinante na formação de um pensamento mais elaborado.

Uma das principais contribuições de David Ausubel para a Educação foi a valorização dada ao conhecimento prévio do aluno. Para Ausubel, o novo conhecimento não se sustenta por si só, ele necessita estar ancorado sobre o conhecimento que o aluno já possui. O conceito principal desenvolvido por Ausubel é o da aprendizagem significativa, a qual declara que "[...] a aprendizagem deve ser uma atividade significativa para a pessoa que aprende e tal significação está diretamente relacionada com a existência de relações entre o conhecimento novo e o que o aluno já possui" (CARRETERO, 1997, p. 15).

Para que a aprendizagem significativa ocorra o novo conhecimento não deve se relacionar de forma discricionária com os esquemas mentais do sujeito. Um conceito importante para entender a aprendizagem significativa é o subsunçor, trata-se de uma proposição uma ideia já presente na estrutura cognitiva capaz de servir de ancoradouro para o novo conhecimento. Graças a ele o novo conhecimento interage de forma significativa na estrutura cognitiva do sujeito.

O uso dessas teorias em sala de aula levou a uma valorização do aluno enquanto sujeito ativo no processo de aprendizagem e não meramente um ser que responde a estímulos. Seu conhecimento prévio, decorrente das suas experiências pessoais, torna-se "[...] condição necessária para construção de novos significados e esquemas" (BITTENCOURT, 2011, p. 189). Tal proposta presume um ensino voltado para construção do conhecimento a partir daquilo que o aluno já sabe, por meio de atividades desafiadoras, de pesquisa e de análise capazes de possibilitar uma aprendizagem significativa. 
A despeito das contribuições desses autores, críticas pertinentes têm sido feitas às suas teorias. Para Carretero (1997), a aprendizagem, pensada por estes psicólogos, é uma atividade solitária, visto que o aluno aprende à margem de seu contexto social. Mesmo que considerem a interação do sujeito com o seu meio importante não analisam, efetivamente, o papel das relações entre o social e o indivíduo no processo de aprendizagem. De acordo com Carretero (1997, p. 25), "[...] a ênfase nos estágios [cognitivos] fez com que se considerasse o professor mais como um espectador do desenvolvimento e favorecedor dos processos de descobrimento autônomo de conceitos do que como um agente que pode intervir ativamente na assimilação de conhecimento".

\section{Construtivismo social}

Tendo em vista as aproximações do presente trabalho com o campo de investigação da Cognição Histórica situada e, por conseguinte, com a teoria pedagógica construtivista, busca-se, aqui, analisar algumas características do Construtivismo. O Construtivismo nasce no bojo da Psicologia Cognitiva e, como apontado por Carretero, não se trata de um termo unívoco. Segundo o autor, trata-se de uma posição compartilhada por diversas correntes de pensamento, entre estas é possível mencionar as teorias de Piaget, Vygotsky e Ausubel.

Conforme Carretero, Construtivismo é

[...] a idéia que sustenta que o indivíduo - tanto nos aspectos cognitivos e sociais do comportamento como nos afetivos não é um mero produto do ambiente nem um simples resultado de suas disposições internas, mas, sim, uma construção própria que vai se produzindo, dia a dia, como resultado da interação entre esses dois fatores (CARRETERO, 1997, p. 10).

O conhecimento, segundo esta corrente, é uma construção do indivíduo resultante da mobilização de fatores internos (inteligência, experiência) e de fatores externos (interação social). A aprendizagem, do ponto de vista construtivista, é "[...] um processo ativo no qual o aluno 
compara, expande, restaura e interpreta o conhecimento, recorrendo à experiência e à informação que a todo o momento recebe" (GAGO, 2012, p. 24). Para o Construtivismo, os níveis de construção do conhecimento não estão inteiramente vinculados a aspectos como idade ou maturidade biológica.

Para que a aprendizagem possa ser considerada eficaz e significativa, o aluno deve operar ativamente sobre a nova informação, assimilando-a. Por assimilação não se entende uma cópia exata do que foi aprendido, mas uma reconstrução. Michel de Certeau, em seu conhecido trabalho $A$ invenção do cotidiano, faz uma interessante reflexão sobre os usos e ressignificações dos textos por parte dos leitores. Essa reflexão pode ser usada quando pensamos na aprendizagem, uma vez que, conforme Certeau, o leitor dotado de táticas, de criatividade e de inventividade não se limita a consumir ou assimilar no sentido de 'tornar-se semelhante' àquilo que leu ou aprendeu. Segundo Certeau (2008, p. 261) - e em consonância com o Construtivismo -, assimilar algo corresponde a "'torná-lo semelhante' ao que se é, fazê-lo próprio, apropriar-se ou reapropriar-se dele". Isto significa romper com a ideia que "[...] a eficácia da produção implica a inércia do consumo" (CERTEAU, 2008, p. 262). Em outras palavras, quem consome age sobre o produto. $O$ consumidor não é um ser passivo, mas, sim, dotado de uma inventividade própria que lhe permite ir além do auspiciado pelos produtores.

Segundo Certeau (2008, p. 269-270), "[...] os leitores são viajantes; circulam nas terras alheias, nômades caçando por conta própria através dos campos que não escreveram, arrebatando os bens do Egito para usufruí-los". Discorrendo sobre a atividade leitora, Certeau assevera que o leitor/aprendiz é capaz de produção própria e lança à História, à Pedagogia escolar e à Sociologia, o desafio de analisar esta produção.

Dentro do paradigma construtivista a habilidade de se apropriar, de fazer próprio e de construir o que se aprende ocorre por meio de esquemas ou construções mentais. Os esquemas são construções de quem aprende e são utilizados para a elaboração de novas situações. Segundo Driver,

Lo que se aprende no depende, pues, solamente de las características de la situación presentada (sea el texto de un 
libro o un fenómeno físico), sino de los «esquemas» que tiene disponibles el que aprende. En otras palabras, el proceso de aprendizaje es una interacción entre los esquemas mentales del que aprende y características del medio de aprendizaje (DRIVER, 1988, p. 111).

A interação constante entre os esquemas que o sujeito possui e a realidade faz com que estes esquemas estejam em constante transformação, tornando-os cada vez mais complexos e sofisticados. É importante ressaltar, no entanto, que a base para a transformação destes esquemas são as próprias ideias prévias ou representações iniciais sobre a nova informação, pois é a partir da interação do novo com os esquemas mentais já presentes que o conhecimento é construído. Desta forma, o construtivismo coloca no centro do processo de aprendizagem o aluno e o conhecimento que ele dispõe, ou seja, suas ideias prévias.

Conforme Gago (2012, p. 26), a ideia prévia é "[...] aquela que o aluno dispõe no seu sistema cognitivo para explicar determinado fenómeno ou conceito. Esta ideia resulta da sua experiência e vivência pessoal própria e individual, face a determinada realidade ou problema". Como apontado por Barca (2001), as diferentes esferas de sociabilidade do aluno (família, meios de comunicação) contribuem para formação do seu conhecimento histórico e, portanto, não devem ser ignorados em sala de aula. Desta forma, a escola perde a exclusividade de locus de aprendizagem e as representações de mundo que os alunos dispõem adquirem centralidade em sala de aula para que uma mudança conceitual ocorra. A mudança conceitual surge do conflito entre as ideias prévias e as científicas. Espera-se que deste conflito resultem ideias mais válidas do ponto de vista disciplinar. Não se trata de um percurso fácil, por isso não basta mapear o que os alunos sabem, é preciso analisar de que forma a interação entre os saberes que possuem reagem aos novos.

Elaborar estratégias educativas, tendo em vista a mudança das representações inicias dos alunos, é um desafio, pois trata-se de ideias bem arraigadas e, por isso, dificilmente são modificadas. Conforme Maria Pereira,

[...] o conhecimento tácito está presente e convocável, pois está ancorado nas experiências idiossincráticas e na matriz cultural dos indivíduos. Sendo estruturas de longa duração, e como tal, resistentes a mudanças abruptas, ele constrói-se através de um diálogo entre os sujeitos e o meio envolvente, procurando encontrar explicações eficazes para as nossas 
próprias contradições, incongruências e conflitos (PEREIRA, 2005, p. 03).

Carretero (1997) traz como exemplo desta dificuldade um trabalho realizado com um grupo de alunos colocados diante de situações que contradiziam suas ideias prévias. O autor notou que alguns não perceberam a existência de incoerências e mantiveram as mesmas ideias; outros mudaram suas concepções por ideias mais simples e incorretas do ponto de vista científico, e um número pequeno de alunos mudou suas ideias. Segundo o autor, o confronto entre ideias prévias e científicas é útil, porém nem sempre os resultados são os esperados. Para Pereira, a persistência destas ideias

[...] deriva da dificuldade dos indivíduos se distanciarem e de exercerem autocrítica; -São fáceis de serem recordadas porque pertencem muitas vezes a contextos vivenciais que foram ou são relevantes para os alunos (sensibilidade, sentimentos, etc.); -Os alunos encontram nelas semelhanças com a situação ou fenômeno científico em estudo, e finalmente - estas ideias persistem porque contém em si mecanismos circulares de auto alimentação e legitimação/reprodução pacíficas (PEREIRA, 2001, p. 45).

Segundo Pereira (2001), quando os alunos são colocados diante a situações de conflito cognitivo ${ }^{4}$ alguns cenários são possíveis. O aluno pode aceitar o novo modificando o próprio conhecimento ou rompendo totalmente com o velho, como também pode adotar estratégias distintas visando manter sua posição. Por exemplo, pode ocorrer uma adição entre as suas ideias e a nova; as duas ideias podem ser consideradas equivalentes; pode selecionar determinados elementos para confirmar sua posição; ou sua ideia é considerada como exceção à regra.

As dificuldades que acompanham o percurso que leva a mudança conceitual não deve indispor, mas ajudar a cartografar os pontos necessários para consecução da tarefa. E, para isso, é de vital importância que o professor conheça essas ideias para poder modificá-las. Afinal, no construtivismo o aluno assume um papel central na construção do seu conhecimento e

\footnotetext{
${ }^{4} \mathrm{O}$ conflito cognitivo ocorre quando as ideias que o aluno já possui são colocadas em confronto com uma nova informação ou situação. O confronto tem por objetivo fazer com que o aluno perceba as insuficiências da primeira. (CARRETERO, 1997, p. 71).
} 
entender este processo deve ser o foco para uma aprendizagem significativa. A consciência da persistência das ideias prévias dos alunos requer, do professor, uma prática que leve em consideração a importância do exercício constante de confrontação entre ideias novas e prévias, de repetição, de exercício e de auxílio. É preciso repensar, constantemente, quais métodos e estratégias adotar para se obter uma progressão do pensamento histórico mais elaborado, por parte dos alunos.

Ainda sobre as características do Construtivismo, além das ideias prévias dos alunos e das estratégias cognitivas por eles adotadas, o professor "[...] deve conhecer a estrutura da disciplina na sua dimensão epistemológica" (GAGO, 2012, p. 23). Ou seja, é necessário repensar os princípios psicopedagógicos à luz dos princípios específicos da disciplina de História. Segundo Barca (2001, p. 20), "[...] a aprendizagem deve processarse no contexto da resposta à natureza da disciplina". Desta forma, a partir de contribuições advindas do Construtivismo é possível articular elementos específicos da disciplina de História para pensar situações concretas de ensino e de aprendizagem visando uma progressão do pensamento histórico dos alunos.

\section{Uma breve panorâmica sobre a Educação Histórica e o conceito de literacia histórica}

A Educação Histórica é um campo de investigação do Ensino de História que se desenvolveu a partir da década de 1970, na Inglaterra, com o objetivo de investigar as ideias de alunos e professores sobre a natureza do conhecimento histórico. Trata-se de uma área de pesquisa em expansão. Vários estudos sobre cognição histórica situada têm sido conduzidos em diversos países como Canadá, Portugal, Espanha, Estados Unidos e Brasil.

Este campo de pesquisa parte da teoria de ensino aprendizagem proposta pelo Construtivismo Social para pensar a aprendizagem histórica. Neste sentido, o Construtivismo é essencial por ressaltar o papel ativo do aluno enquanto sujeito do processo de aprendizagem, como também por 
apontar a importância do mapeamento dos conhecimentos prévios apresentados, tendo em vista alcançar uma mudança conceitual e progressiva do pensamento histórico de quem aprende.

Em oposição a uma concepção evolutiva do desenvolvimento cognitivo com base na idade, nos moldes de Piaget, ou de um Ensino de História validado pela quantidade de informações que o aluno era capaz de reter, a Educação Histórica propõe analisar a cognição em História com base na própria racionalidade da História. De fato, a característica peculiar desta área de investigação é ter "[...] como pressuposto teórico [...] a natureza do conhecimento histórico e, como pressuposto metodológico, a análise de ideias que os sujeitos manifestam em e acerca da História, através de tarefas concretas" (BARCA, 2001, p. 13).

De acordo com Márcia Ramos e Marlene Cainelli (2015, p. 24),

[...] a investigação em Educação Histórica tem como objetivo entender as relações que alunos e professores estabelecem com o conhecimento histórico, com seus conceitos e categorias históricas. A pesquisa em Educação Histórica tem especial interesse na forma pela qual o trabalho com fontes, incluindo os objetos históricos, as estratégias de ensino, os materiais didáticos, entre outros, colaboram para com a formação do pensamento histórico e para com a consciência histórica de alunos e professores.

As ideias históricas de alunos e professores se tornaram objeto de análise nas pesquisas sobre cognição histórica na Inglaterra em um contexto de debate sobre reestruturação curricular. Segundo Peter Lee (2001, p. 13), nos anos 1960, "[...] surgiu o receio de que os alunos deixassem de estudar História, o que de fato quase aconteceu. Existia um currículo descentralizado em Inglaterra e poucos alunos escolhiam a disciplina de História". O pouco interesse suscitado encontrava justificativa no fato de que a disciplina era reputada como tediosa e sem finalidade prática pelos alunos.

Objetivando reverter esta situação foi elaborado o The History 13-16 Project sob a coordenação de Peter Lee e, posteriormente, de Denis Shemilt. Este programa teve como público alvo jovens de 13 a 16 anos, e foi colocado em prática em mais de um terço das escolas da Inglaterra. Estes pesquisadores partilhavam da convicção de que "[...] para compreendermos 
a História, precisamos de falar de situações específicas do passado e de promovermos a sua interpretação" (LEE, 2001, p. 14).

O trabalho com fontes em sala de aula possibilitou uma aproximação com a metodologia da disciplina e o desenvolvimento de habilidades importantes para a análise contextualizada e de crítica documental. O uso de fontes em sala de aula vem a corroborar a ideia de que não basta um conhecimento baseado nos conceitos substantivos. É necessário que os alunos compreendam os conceitos meta históricos, ou de segunda ordem, próprios da ciência da história. Como colocado por Marilia Gago (2012, p. $61)$, os conceitos de segunda ordem "[...] providenciam a compreensão da História como uma forma de conhecimento, isto é, mostram como se faz História, e que conceitos se constroem, como causa, evidência, narrativa, mudança $[\ldots]^{\prime \prime}$. Lee declarou que:

\section{[...] com o Projecto as crianças passaram a olhar para a História como uma disciplina interessante e difícil como a matemática [...]. Com efeito, um dos objetivos do Projecto era fazer da História uma disciplina séria. Era necessário haver algo que as crianças apreendessem progressivamente, que se operassem mudanças nas ideias e que elas conseguissem perceber essas mudanças (LEE, 2001, p. 14).}

No CHATA Project (Concepts of History and Teaching Approaches), estes pesquisadores aprofundaram os estudos anteriores ao investigarem como os alunos lidavam com narrativas divergentes sobre um mesmo tema histórico. Este estudo foi posto em prática em crianças de 6 a 14 anos, em um total de 320 alunos. A pesquisa foi desenvolvida em várias fases, nas quais os alunos foram interpelados a responder questões sobre compreensão de causas em História; empatia; objetividade da pesquisa histórica; evidência e narrativa.

Uma das tarefas que os alunos tiveram que responder dizia respeito a ocupação romana das ilhas britânicas. Foram apresentados dois textos com narrativas divergentes sobre a ocupação das ilhas, e os alunos foram solicitados a responder como podia haver diferenças ao contar-se a mesma história? As ideias históricas, contidas em cada uma das narrativas recolhidas, foram organizadas em níveis partindo de ideias mais simples para um nível mais elaborado. De acordo com Lee (2001), alguns alunos não 
perceberam que se tratavam de narrativas contraditórias, outros assentiram que a diferença era devido a maneira de contar, uns porque não foi possível para os historiadores encontrarem todas as informações a respeito do tema e, assim, elas podem estar incompletas ou ser inventadas, alguns alunos apontaram para a questão do ponto de vista e, enfim, outros concluíram que as diferenças são um fator intrínseco à natureza do conhecimento histórico.

A partir destes estudos, Lee concluiu que com o avançar da idade o número de alunos que apresentaram um nível mais elaborado de pensamento histórico foi maior. No entanto, alunos com 7 e 8 anos também se alocaram em níveis mais sofisticados. Segundo o autor, "[...] há crianças que já sabem que as histórias não são cópias do passado, elas são construídas. Se dermos apenas factos a estas crianças, estaremos a desiludi-las" (LEE, 2001, p. 20). Portanto, a pesquisa rompeu com a ideia de que os alunos quando avançam em idade, naturalmente também avançam em sua explicação histórica, e, se há "avanços", são outros os fatores que contribuem para tal.

Estas atividades permitiram investigar o grau de sofisticação das ideias históricas apresentadas pelos alunos. A progressão do pensamento histórico é mensurada com base na própria episteme da História e não em estágios de desenvolvimento, como proposto por Piaget. No projeto 13-16 a tarefa desenvolvida pelos alunos "[...] funcionou como um desafio positivo e aliciante, o que pode confirmar a hipótese de que a compreensão dos métodos, lógica e perspectivas da História pelos alunos pode ser progressivamente desenvolvida" (GAGO, 2012, p. 79).

Para Lee (2008) uma vez reconhecido que a aprendizagem histórica perpassa pela compreensão da natureza da História, é possível pensar em viabilizar o desenvolvimento de uma progressão conceitual. Não em um sentido restrito que prevê apenas uma acumulação de informação, e sim no que tange ao desenvolvimento progressivo de ideias históricas mais elaboradas. De acordo o autor, o conceito de progressão consente uma "[...] mudança de ideias deficitárias de senso-comum, que não permitem ou reduzem a possibilidade de compreensão ou explicação histórica, para ideias que a tornem possível" (LEE, 2008, p. 15). 
Ao ressaltar a importância dos conceitos de segunda ordem, o autor não subestima a relevância de conceitos substantivos, ligados aos conteúdos da disciplina, para a consecução de uma aprendizagem histórica significativa. O conúbio entre os conceitos substantivos e de segunda ordem é tido como essencial. É graças aos conceitos meta históricos que os conteúdos aprendidos podem ser operados de forma mais eficaz. Conforme Lee (2008, p. 19), trabalhar para desenvolver a progressão "[...] significa equipar os alunos com ideias mais sofisticadas/poderosas, por exemplo acerca de como nós podemos conhecer o passado e por que é que as narrativas históricas dos historiadores diferem".

Além da compreensão da disciplina de História a Educação Histórica atribui uma função social à aprendizagem histórica. Conforme Ronaldo Cardoso Alves (2011, p. 35), "[...] o ensino de História propicia condições aos alunos de forma tal que possam adentrar o passado, por meio do raciocínio histórico, com o objetivo de diagnosticar as questões fulcrais do presente com o fim de antecipar o futuro".

A partir da década de 1990, iniciou-se um diálogo entre os pesquisadores da Educação Histórica com os pesquisadores alemães da Didática da História, o que resultou na inserção nas pesquisas do conceito de consciência histórica, proposto por Jörn Rüsen. Segundo ele, a consciência histórica seria a aplicação do conhecimento histórico na práxis, ou seja, o conhecimento sobre o passado atuaria como um fator de orientação temporal na vida prática. No entanto, o autor adverte que a orientação temporal nem sempre ocorre mediante preceitos históricos, pois aspectos como sensocomum, preconceitos, sentimentos de pertença e questões identitárias podem interferir nas tomadas de decisão. Para Rüsen, a formação histórica é - meio para garantir que a orientação temporal seja baseada em pressupostos históricos. Sendo assim, formação histórica é,

O conjunto das competências de interpretação do mundo e de si próprio, que articula o máximo de orientação do agir com o máximo de auto- realização ou de reforço identitário. Trata-se de competências simultaneamente relacionadas ao saber, à práxis e à subjetividade. [...] A categoria da formação referese à vinculação entre saber e agir exigida pela carência de orientação do sujeito agente, pois insere-se na representação do todo que constitui a situação em que o agente deve lidar 
com seus problemas. Formação leva muito a sério esse direcionamento à carência de orientação (RÜSEN, 2010, p. 95).

A formação é uma categoria da Didática da História responsável pela relação entre saberes científicos e seus usos práticos. Segundo Rüsen (2010), a formação histórica possibilita a integração do saber histórico obtido pela pesquisa em saberes históricos relevantes para a práxis e eficazes para orientação. A subjetividade reside não na acumulação de saberes, mas com as formas de lidar com estes e aplicá-los aos problemas de orientação. Se trata de um processo dinâmico de reelaborar, continuamente, saberes na orientação da vida prática.

O conceito de aprendizagem de Rüsen se encontra extremamente vinculado a categoria da formação histórica, pois aprender pode ser definido como a "[...] elaboração da experiência na competência interpretativa ativa, e formação histórica não mais é do que uma capacidade de aprendizado especialmente desenvolvida" (RÜSEN, 2010, p. 104). Para o autor, o aprendizado histórico ocorre quando um dado objetivo que ocorreu no passado torna-se subjetivo e, em seguida, passa a desempenhar um papel no ordenamento interno no sujeito. Segundo Rüsen (2010; 2014), o movimento de aprendizado é duplo: em um primeiro momento tem-se a passagem do dado objetivo à apropriação subjetiva e, em seguida, da busca subjetiva de afirmação de si ao entendimento objetivo. Esse duplo movimento de aprendizagem de aquisição do conhecimento histórico, por meio da experiência e auto realização, se dá através de quatro operações, isto é, a experiência, a interpretação, a orientação e a motivação.

Rüsen assevera que a aprendizagem histórica comporta o crescimento da experiência sobre os saberes que aconteceram no passado. Mas não basta saber o que ocorreu no passado, é preciso saber distinguir, qualitativamente, entre o passado e o presente e que, mesmo se tratando de diferentes temporalidades, permanências do passado se encontram no presente. É importante, ainda, saber relacionar esse saber do passado no presente no quadro de orientação da vida prática. Se trata de uma aquisição ativa dessa experiência do passado. 
Conforme Schmidt, Barca e Martins (2010), a aprendizagem histórica aumenta a capacidade para encontrar significado. O aumento da experiência e do saber transforma-se numa mudança produtiva dos modelos de interpretação, também chamado de quadro histórico. Esses modelos são flexíveis, dinâmicos e se modificam qualitativamente. De acordo com a autora, os modelos tradicionais se tornam exemplares, os exemplares, críticos, e os críticos, genéticos. O processo de aprendizagem pode ser descrito como a passagem de um dogmatismo quase natural das posições históricas à colocação do saber histórico em perspectiva.

Para Rüsen (2010; 2014), a aprendizagem histórica acarreta, também, no aumento da competência de orientação e motivação do agir. Trata-se da capacidade dos sujeitos de correlacionar os modelos de interpretação, cheios de experiência e saberes, com seu próprio presente e com sua própria vida. As quatro dimensões do aprendizado histórico estão interligadas. É ainda comum considerar que quanto maior o volume de informações mais História se aprende. O problema é que o saber apropriado apenas de forma passiva não fomenta a capacidade de interpretação das experiências, nem sua utilização para fins de orientação na vida prática. É importante que haja equilíbrio entre a História como dado objetivo e a História como construto subjetivo da orientação prática. Segundo Lee, o objetivo da aprendizagem histórica deveria ser a formação de uma literacia histórica, ou seja, desenvolver nos alunos a capacidade de ler o mundo historicamente.

No Dicionário Priberam da Língua Portuguesa a palavra literacia é definida "[...] como capacidade de ler e de escrever; capacidade para perceber e interpretar o que é lido" ${ }^{5}$. O conceito de literacia histórica aplicado neste trabalho tem como referência a definição desenvolvida por Peter Lee, a partir de considerações filosóficas de autores como Collingwood, Lorenz, Oakeshott e Rüsen, do qual Lee utiliza o conceito de consciência histórica. Literacia histórica, para Lee, ultrapassa o simples ato de ler ou entender. Trata-se da capacidade de compreensão da disciplina de História, associada

\footnotetext{
${ }^{5}$ Dicionário Priberam da Língua Portuguesa [em linha], https://www.priberam.pt/dlpo/literacia [consultado em 25 - 02 - 2016].
} 
a uma estrutura utilizável do passado capaz de fornecer orientação para vida prática (LEE, 2006, p. 145).

O conceito de literacia histórica prevê a investigação das ideias dos estudantes sobre a disciplina de História, como também busca entender de que forma o conhecimento histórico é mobilizado para fins de orientação para vida prática e para construção de projeções de futuro.

Segundo Rüsen, a capacidade de orientação temporal é uma característica antropológica. Esta habilidade é definida como consciência histórica e, segundo o autor, se trata da "[...] soma das operações mentais com as quais os homens interpretam sua experiência de evolução no tempo do seu mundo e de si mesmos, de forma tal que possam orientar, intencionalmente, sua vida prática no tempo" (RÜSEN, 2011, p. 57).

O conceito de literacia histórica é mais específico que o de consciência histórica de Rüsen, pois como aponta Lee, "[...] a consciência histórica é mais ampla do que o tipo de alfabetização histórica que deve ser oferecida por uma educação histórica e nem todas as formas de consciência histórica atendem aos padrões da história"6 (LEE, 2011, p. 61). O conceito de literacia histórica abarca o conceito de consciência histórica, entretanto a orientação para a vida prática deve estar ancorada a pressupostos da disciplina de História e não por ideias pautadas no senso comum, na tradição, em sentimentos de identidade ou de pertença. Afinal, "[...] o pensamento histórico requer uma orientação para o passado pautados em evidências e regras de argumentação"7 (WINEBURG, 2007, p. 6).

Como apontado por Schimdt (2009), à diferença das teorias psicológicas sobre ensino e aprendizagem, os componentes necessários para o desenvolvimento da literacia histórica se encontram ancorados em pressupostos pautados na racionalidade da ciência História e, portanto, pode ser definida como cognição histórica situada.

\footnotetext{
${ }^{6}$ Tradução livre da autora. No original "[...] historical consciousness is wider than the kind of history literacy that should be offered by a history education, and not all forms of historical consciousness meet the standards of history" (LEE, 2011, p.61).

${ }^{7}$ Tradução livre da autora. No original "[...] historical thinking requires an orientation to the past informed by disciplinary canons of evidence and rules of argument" (WINEBURG, 2007, p. 6).
} 
A ênfase na ciência de referência deve-se ao fato que "[...] la historia es un conocimiento que posee unas particularidades que exigen para su enseñanza la comprensión de su propia formulación" (GÓMEZ; ORTUÑO; MOLINA, 2014, p. 8). Para Carretero (1997, p. 9), "[...] não é mais possível falar de uma capacidade cognitiva do tipo geral, senão que a inteligência, o conhecimento, ou como se lhe queira chamar, desenvolve-se em relação com a compreensão de conteúdos específicos, que têm a ver com as distintas matérias escolares".

Como já assinalado, uma das ferramentas necessárias para o desenvolvimento da literacia histórica apontada por Lee é a compreensão da disciplina de História. Conforme o autor, é preciso que "[...] os alunos entendam algo do que seja história, como um compromisso de indagação. (...) Isso sugere que os alunos devem entender, por exemplo: como o conhecimento histórico é possível, o que requer um conceito de evidência" (LEE, 2006, p. 116). A partir dessas ideias, as fontes históricas utilizadas na produção do conhecimento histórico passam a ser vistas não como meros veiculadores de informação, mas como suportes para questionamentos e análise histórica visando interpretações plausíveis sobre o passado.

É importante que os alunos entendam que a narrativa histórica não é uma cópia exata do passado, que o conhecimento histórico se dá de forma indireta a partir de vestígios e das inferências elaboradas a partir de sua análise. Para Lee (2006, p. 140), "[...] a compreensão de como as afirmações históricas podem ser feitas, e das diferentes formas nas quais elas possam ser mantidas ou desafiadas, é uma condição necessária para a literacia histórica".

Outro componente importante para o entendimento da natureza do saber histórico perpassa a compreensão contextualizada das ações dos sujeitos do passado. O que pressupõe o conceito de empatia, enquanto o entendimento:

[...] das crenças e valores das pessoas do passado são entendidos como não necessariamente os mesmos que os nossos, e até mesmo considerados estranhos, todavia eles ainda são reconhecidos como inteligíveis e defensável em seus 
próprios termos e ajudam a dar sentido às crenças e valores do presente ${ }^{8}$ (LEE, 2011, p. 145).

Sendo assim, a compreensão da disciplina de História está intimamente ligada ao próprio oficio do historiador, e, portanto, não se resume apenas a memorização de conteúdos sobre acontecimentos e datas do passado. Os autores fazem notar que:

La comprensión histórica implica unos complejos procesos de pensamiento que permitan interpretar esos contenidos (conceptos de primer orden), a través de estrategias propias de la disciplina (conceptos estratégicos o de segundo orden). Para adquirir estas habilidades es necesario la participación de los alumnos en la práctica del historiador (GÓMEZ; ORTUÑO; MOLINA, 2014, p. 5).

De acordo com o conceito de literacia histórica, a compreensão do conhecimento histórico decorre do desenvolvimento de competências vinculadas a própria epistemológica da História. Conforme Lee, a compreensão histórica é uma forma de ver o mundo, o que implica entender:

[...] as idéias-chaves que tornam possível o conhecimento do passado e os diferentes tipos de afirmações feitas pela história, incluindo o conhecimento de como inferimos e testamos as declarações, explicamos eventos e processos e narramos o passado ${ }^{9}$ (LEE, 2011, p. 140).

Além dos conceitos substantivos ou de primeira ordem, ligados aos conteúdos disciplinares, a Educação Histórica propõe, também, trabalhar com conceitos de segunda ordem em sala de aula. Os conceitos de segunda ordem ou conceitos meta históricos permitem a compreensão da construção do saber histórico, ou seja, revelam como se faz a História. São conceitos como evidência, narrativa, explicação, mudança, empatia. Este tipo de "[...] conocimientos históricos están relacionados con habilidades propias del historiador que se concretan en: la búsqueda, selección y tratamiento de fuentes históricas" (GÓMEZ; ORTUÑO; MOLINA, 2014, p. 9).

\footnotetext{
${ }^{8}$ Tradução livre da autora. No original "[...] the beliefs and values of people in the past are understood as not necessarily the same as ours, and even as passing strange, but they are still recognized as intelligible and defensible in their own terms, and as helping make sense of present beliefs and values" (LEE, 2011, p. 145).

${ }^{9}$ Tradução livre da autora. No original "[...] the key ideas that make knowledge of the past possible, and of the different kinds of claims made by history, including knowledge of how we infer and test statements, explain events and processes, and give accounts of the past" (LEE, 2011, p. 140).
} 
Um dos empecilhos para se alcançar a compreensão histórica decorre da pouca importância dada aos conceitos de segunda ordem. Segundo Lee (2011), mesmo com todas as reflexões feitas a respeito, é ainda recorrente pensar a disciplina escolar de História como um emaranhado de informações a serem aprendidas. Versões mais engajadas sobre a aprendizagem histórica chegam a considerar a importância da compreensão histórica, mas não percebem sua relação com os conceitos específicos da disciplina. Para o autor, é como "[...] se as ferramentas mais poderosas disponíveis para as crianças fossem ocultadas ou escondidas delas, e a própria base da 'autonomia' obscurecida"10 (LEE, 2011, p. 134).

Para que o passado se torne uma ferramenta poderosa de orientação temporal a compreensão do conhecimento histórico deve estar atrelada a uma História substancial. A dicotomia sustentada pela ideia que contrapõe conteúdo à conceitos de segunda ordem, é prejudicial para consecução da literacia histórica. Como colocado por Lee, a transformação que a literacia proporciona na forma de ver e atuar no mundo ocorre "[...] através e na presença do conhecimento histórico substantivo em que passado e presente não são desvinculados um do outro"11 (LEE, 2011, p.146).

Após esclarecer a importância do conhecimento substantivo da História o autor destaca a dificuldade de fornecer aos alunos um grande quadro do passado. A História que os alunos aprendem é fragmentada, esboçada e baseada, predominantemente, em eventos bem específicos. O passado, na maioria das vezes, aparece como desvinculado do presente, como se as decisões do presente ou projeções de futuro não fossem engendradas a partir dele. O Ensino de História, posto nestas condições, impede que os alunos desenvolvam um quadro mais organizado e útil do passado. De acordo Lee, uma estrutura histórica utilizável deveria abarcar:

[...] um ponto de vista geral de padrões de mudanças a longo prazo, não um mero esboço de história folheando picos do passado. Deve ser ensinada rapidamente e sempre revisitada, pois assim os alunos podem assimilar novas histórias em

\footnotetext{
${ }^{10}$ Tradução livre da autora. No original "It is as if the most powerful tools available to children are to be concealed or withheld from them, and the very basis of 'autonomy' obscured" (LEE, 2011, p. 134).

${ }^{11}$ Tradução da autora. No original "[...] through and in the presence of substantive historical knowledge in which past and present are not cut off from one another" (LEE, 2011, p.146).
} 
relação à estrutura existente ou adaptar a mesma. Seguindo Rüsen, essa matéria deve ser a história humana, não alguns subconjuntos privilegiados dela. Uma UHF irá seguir, inicialmente, amplos desenvolvimentos nas sociedades humanas, questionando sobre os padrões de mudança na subsistência humana e na organização política e social (LEE, 2006, p. 146-147).

Para fornecer um grande quadro do passado, o Ensino de História necessitaria abster-se de histórias eventificadas. Os alunos devem ser orientados a entender a história da humanidade como um todo e não apenas como uma coleção de fragmentos colocados em ordem cronológica. Para Gago (2012), este grande quadro do passado deve ser elaborado pelos alunos e, por se tratar de uma estrutura aberta, pode ser constantemente revisitada com base no que é aprendido ao longo do seu percurso de aprendizagem. Segundo Lee, "[...] o objetivo é usar o quadro continuamente, modificandoo e dando aos alunos o espaço para desenvolver uma visão mais ampla do passado"12 (LEE, 2011, p. 145). Uma UHF (estrutura histórica utilizável) permite que o aluno entenda que não existe uma fronteira que delimita 0 passado do presente, e torna possível que ele se localize no tempo e veja o passado como vinculante para sua orientação no presente e no futuro.

\section{Conclusões}

Concomitantemente aos debates mais atuais sobre aprendizagem, que vêm ocorrendo em áreas como a da Educação Histórica, persistem, ainda, concepções pautadas em preceitos teóricos que se cria já superados. A recusa de considerar o aluno como sujeito ativo no processo de aprendizagem se reflete nas dinâmicas perpetuadas em sala de aula. As ideias previas dos alunos continuam a ser ignoradas, estes são ainda percebidos como recipientes vazios que necessitam ser preenchidos por um conhecimento que Ihes é exterior. A idade, ainda, é considerada um empecilho para se discutir conceitos considerados muito abstratos para serem mobilizados por

\footnotetext{
${ }^{12}$ Tradução da autora. No original "[...] the aim is to use the framework continuously, modifying it and giving students the space to develop big pictures of the past" (LEE, 2011, p. 145).
} 
educandos que, em conformidade com teorias biologizantes, seriam, ainda, imaturos cognitivamente. As atividades, muitas vezes, se encaixam no que se pode classificar de exercícios puramente mnemônicos, privados de teor reflexivo ou crítico. Trata-se de uma concepção mecanicista de aprendizagem, validada pela quantidade de informações que o aluno é capaz de recordar, e não pela relação orientacional significativa que ele é capaz de manter com a História.

De acordo com a Educação Histórica, a aprendizagem histórica ocorre quando o aluno é capaz de vincular a experiência do tempo à sua própria subjetividade, dotando-a de significância e usos para sua vida prática. Apenas quando a História deixa de ser ensinada como um emaranhado de informações que devem ser absorvidas, e passa a ser considerada uma atividade fruto de levantamento de hipóteses e respostas possíveis, poderá ser apropriada pelos alunos de forma significativa e se tornar fator de orientação em sua práxis. A Educação Histórica objetiva desenvolver, nos alunos, competências ou ferramentas intelectuais essenciais à vida social. A capacidade de ler o mundo historicamente permite situar-se e intervir nele de forma crítica e autônoma.

A conquista da literacia histórica transforma o modo que o aluno vê o mundo e permite a sua atuação nele de forma consciente. Conforme Lee, este deveria ser o objetivo principal do Ensino de História. Um ensino capaz de formar jovens engajados e emancipados deve se preocupar em dotá-los de ferramentas conceituais com as quais serão capazes de aprender a pensar por si mesmos.

Sam Winenburg (2007, p.11) adverte que "[...] em um mundo dominado por apelos emocionais, citações arrancadas de contexto, linguagem incendiária e análises jornalísticas que visam extinguir a sobriedade em vez de cultivá-la, o papel de um pensamento histórico tão unnatural nunca pareceu tão urgente"

\footnotetext{
${ }^{13}$ Tradução da autora. No original "In a world dominated by emotional appeals, quotations ripped out of context, incendiary language, and journalistic analyses that aim at extinguishing sobriety rather than cultivating it, the role of such unnatural historical thinking has never seemed more imperative" (WINEBURG, 2007, p. 11).
} 


\section{Referências}

ALVES, Ronaldo Cardoso. Aprender história com sentido para vida: consciência histórica em estudantes brasileiros e portugueses. 2011. 322p. Tese (Doutorado em Educação) - Faculdade de Educação da Universidade de São Paulo.

BARCA, Isabel. Educação Histórica: uma nova área de investigação. Revista da Faculdade de Letras, Porto, v. 2, p.13-21, 2001.

BECKER, Fernando. O que é construtivismo? Idéias, São Paulo: FDE, n. 20, p. 87-93, 1993.

BITTENCOURT, Circe Maria Fernades. Ensino de história: fundamentos e métodos. 4. ed. São Paulo: Cortez, 2011.

BRUNER, Jerome S. The act of discovery. Harvard Educational Review, Cambridge, v. 31, p. 21-32, 1961.

CARRETERO, Mario. Construtivismo e educação. Porto Alegre: Artmed, 1997.

CAIMI, Flávia Eloísa. História escolar e memória coletiva: como se ensina? Como se aprende?. In: ROCHA, Helenice et al. (Org.). A escrita da história escolar: memória e historiografia. Rio de Janeiro: Ed. FGV, 2009. p. 65-79.

CAINELLI, Marlene; OLIVEIRA, Sandra Regina Ferreira de. A relação entre o aprendizado histórico e formação histórica no processo de ensinar história para crianças. In: CAINELLI, Marlene; SCHMIDT, Maria Auxiliadora.

Educação histórica: teoria e pesquisa. Ijuí: Ed. Unijuí, 2011. p. 123-140.

CERTEAU, Michel de. A invenção do cotidiano. 15. ed. Petrópolis: Vozes, 2008.

DARSIE, Marta Maria Pontin. Perspectivas epistemológicas e suas implicações no processo de ensino e de aprendizagem. Uniciências, Cuiabá, v. 3, p. 9-21, 1999.

DRIVER, Rosalind. Un enfoque constructivista para el desarrollo del currículo em ciencias. Enseñanza de las Ciencias, Barcelona, v. 6, n. 2, p. 109-120, 1988.

GAGO, Marilia. Pluralidade de olhares: construtivismo e multiperspetiva no processo de aprendizagem. Maputo: EPM -CELP, 2012. 
GÓMEZ, Cosme Jesús; ORTUÑO, Jorge; MOLINA, Sebastián. Aprender a pensar históricamente. Retos para la historia en el siglo XXI. Revista Tempo e Argumento, Florianópolis, v. 6, n. 11, p. 5-27, 2014.

KAMII, Constance. Reinventando a aritmética: implicações da teoria de Piaget. 3. ed. Campinas, SP: Papirus, 1990.

LEE, Peter. Progressão da compreensão dos alunos em história. In: BARCA, I. (Org.). Perspectivas em educação histórica. Actas das Primeiras Jornadas Internacionais de Educação Histórica. Braga: Centro de Estudos em Educação e Psicologia, Universidade do Minho, 2001. p. 13-29.

. Em direção a um conceito de literacia histórica: Towards a concept of historical literacy. Educar, Curitiba, n. especial, p. 131-150, 2006.

Educação Histórica, consciência histórica e literacia histórica. In. BARCA, I. (Org.). Estudos de consciência histórica na Europa, América, Ásia e África. Braga: Uminho, 2008. p. 11-32.

. Historical literacy and transformative history. In: PERIKLEOUS, Lukas; SHEMILT, Dennis. (Ed.). The future of the past: why history education matters. Nicosia, Cyprus: Association for Historical Dialogue and Research, 2011. p. 129-167.

LIMA, Elvira Cristina Azevedo Souza. O conhecimento psicológico e suas relações com a educação. Em Aberto, Brasília, v. 9, n. 48, p. 3-24, out./dez. 1990.

"LITERACIA", In: Dicionário Priberam da Língua Portuguesa [em linha], https://www.priberam.pt/dlpo/literacia [consultado em 25 - 02 - 2016].

PEREIRA, Maria do Céu de. O conhecimento tácito histórico dos alunos. In: XXIII SIMPÓSIO NACIONAL DE HISTÓRIA - ANPUH, 23, 2005, Anais...Londrina: Editorial Mídia, 2005. p. 01-09.

O conhecimento tácito substantivo histórico dos alunos: no rastro da escravatura. In: BARCA, Isabel (Org.). Perspectivas em educação histórica. Braga: Universidade do Minho; Centro de Estudos em Educação e Psicologia, 2001. p. 45-54.

POZO, J. Ignacio. Teorías cognitivas del aprendizaje. 9. ed. Madrid: Ediciones Morata, 2006.

RAMOS, Márcia; CAINELLI, Marlene. A educação histórica como campo investigativo. Diálogos, Maringá, v. 19, n.1, p. 11-27, 2015.

RÜSEN, Jörn. Razão histórica. Brasília: Editora Universidade de Brasília, 2011. 
História viva: teoria da história: formas e funções do conhecimento histórico. Brasília: Editora Universidade de Brasília, 2010.

Cultura faz sentido: orientações entre o ontem e o amanhã.

Petrópolis: Vozes, 2014.

SCHMIDT, Maria Auxiliadora. Cognição histórica situada: que aprendizagem histórica é esta. In: SCHMIDT, Maria Auxiliadora, BARCA, Isabel. (Org.). Aprender história: perspectivas da educação histórica. Ijuí: Editora UNIJUÍ, 2009. (Coleção Cultura, Escola e Ensino). p. 21-51.

SCHMIDT, Maria Auxiliadora; BARCA, Isabel; MARTINS, Estêvão Rezende (Org.). Jörn Rüsen e o ensino de História. Curitiba-PR: Editora UFPR, 2010.

SEBER, Maria da Gloria. Construção da inteligência pela criança: atividades do período pré-operatório. 2. ed. São Paulo: Scipione, 1991.

WINEBURG, Sam. Unnatural and essential: the nature of historical thinking. Teaching History, London, n. 129, p. 6-11, 2007. 